Universidade Tecnológica Federal do Paraná - UTFPR

Campus Ponta Grossa - Paraná - Brasil

ISSN: 1981-3686/ v. 9, n.2: p. 1875-1887, 2015

D.O.I.:10.3895/rbta.v9n2.2028

\author{
Revista Brasileira de Tecnologia \\ Agroindustrial
}

\title{
SECAGEM DA POLPA DE CAJU EM SECADOR DE LEITO DE JORRO
}

\section{DRYING OF CASHEW PULP IN SPOUTED BED DRYER}

\author{
Dyego da Costa Santos ${ }^{1}$; Emanuel Neto Alves de Oliveira ${ }^{2}$; \\ Joabis Nobre Martins ${ }^{3}$; Ana Paula Trindade Rocha ${ }^{4}$ \\ ${ }^{1,4}$ Universidade Federal de Campina Grande - UFCG - Campina Grande - PB - Brasil \\ dyego.csantos@gmail.com \\ ${ }^{2}$ Instituto Federal de Educação, Ciência e Tecnologia do Rio Grande do Norte - IFRN - Pau dos Ferros - \\ $\mathrm{RN}-$ Brasil \\ ${ }^{3}$ Instituto Federal de Educação, Ciência e Tecnologia Sertão Pernambucano - IF Sertão - Salgueiro - PE - \\ Brasil
}

\begin{abstract}
Resumo
Objetivou-se secar polpa de caju em secador de leito de jorro, caracterizar físico-quimicamente os pós produzidos e avaliar o processo de secagem no secador utilizado. A polpa de caju foi adicionada de $10 \%$ de maltodextrina e submetida às secagens nas temperaturas de 50,60 e $70{ }^{\circ} \mathrm{C}$. Os pós produzidos foram analisados quanto ao teor de umidade, açúcares totais, acidez total titulável em ácido cítrico, pH, cinzas, atividade de água e cor, com obtenção dos parâmetros de luminosidade $\left(L^{*}\right)$, e cromaticidades $a^{*} e b^{*}$. Quanto ao processo de secagem foram avaliadas a taxa de remoção do produto (rendimento), a taxa de acúmulo no secador e a taxa de evaporação do leito de jorro. Observou-se que o teor de umidade, a atividade de água e o pH reduziram significativamente com o aumento da temperatura de secagem. Houve concentração das cinzas $e$ aumento significativo nos valores de açúcares totais e acidez total com o aumento da temperatura. A elevação da temperatura de secagem promoveu clareamento significativo nos pós. A taxa de recuperação do produto aumentou com o aumento da temperatura de secagem e a taxa de acumulo diminuiu com a temperatura. A taxa de evaporação não variou. A secagem em leito de jorro é uma boa opção para obtenção da polpa de caju em pó, com melhores resultados dos parâmetros analisados para o pó produzido a $70^{\circ} \mathrm{C}$.
\end{abstract}

Palavras-chave: Anacardium occidentale L., desidratação, controle de qualidade, análises químicas.

\section{Introdução}

O cajueiro (Anacardium occidentale L.) é uma planta rústica, originária do Brasil, sendo típica de regiões de clima tropical. Trata-se de uma árvore popular na América do Sul, sendo especialmente encontrada nas regiões Norte e Nordeste do Brasil (SANCHO et al. 2007). O cultivo do caju é uma das principais atividades do Nordeste com produção de cerca de 200 mil toneladas de amêndoas e dois milhões de toneladas de pedúnculo (PINHO et al., 2011), também chamado de 
pseudofruto. São encontradas no Brasil duas variedades de pseudofruto, uma com a pele de cor amarela e outra de cor vermelha, mas ambas com a mesma polpa amarela pálida (ALCÂNTARA et al., 2009).

O processamento do caju para obtenção de polpa é uma atividade agroindustrial importante, na medida em que agrega valor econômico ao pseudofruto, evitando desperdícios e minimizando perdas que podem ocorrer durante a comercialização do produto in natura (PEREIRA et al., 2006), no entanto torna-se necessário estudos de técnicas de processamento e preservação alternativos (CABRAL et al., 2007). Nesse contexto, a secagem da polpa de caju para obtenção de pó é uma boa alternativa para agregar valor ao pseudofruto ao passo que estende sua vida útil devido à redução da atividade de água do produto a níveis seguros $(<0,6)$, permitindo então o armazenamento por longos períodos. Além disso, a polpa de caju em pó poderá se constituir em opção de ingrediente atrativo para utilização em diferentes formulações de alimentos.

Dentre os métodos de secagem propostos para polpa de frutas, têm-se o de leito de jorro. Este processo foi apresentado na literatura como uma alternativa atraente para a secagem de pastas e de suspensões, com produção de um pó de alta qualidade e baixo custo (BEZERRA et al., 2013). Nas ultimas décadas este tipo de secagem vem sendo utilizado na área agrícola, devido à necessidade de aumento da produtividade de alimentos (ALMEIDA; ROCHA, 2002). De acordo com Gomes et al. (2004), a técnica de secagem em leito de jorro têm evoluído consideravelmente, ocupando importante lugar no processamento de alimentos em substituição ao "spray dryer".

Experimentos com o leito de jorro para a secagem de polpa de frutas tem-se ampliado a cada dia, obtendo-se produtos com boa qualidade, no entanto Pallai et al. (2006) afirmam que, embora a qualidade do pó atenda aos requisitos básicos para o uso comercial, alguns aspectos podem dificultar a sua aplicação, como a estabilidade do jorro, a aglomeração de partículas e depósitos de pó dentro do leito.

$\mathrm{Na}$ literatura estão disponíveis alguns estudos de desidratação de polpas de frutas em secador de leito de jorro, como acerola (GOMES; FIGUEIRÊDO; QUEIROZ, 2004), umbu, seriguela manga, pinha, abacate (MEDEIROS et al., 2001), banana verde (BEZERRA et al., 2013), cajá (MELO et al., 2010), tomate longa vida (LARROSA; MUSZINSKI; PINTO, 2011), entre outros, no entanto são escassas informações sobre a obtenção de pós a partir da polpa de caju, inclusive com o uso de aditivos carreadores, como a maltodextrina, que auxiliam no processo de secagem. Segundo Martins (2006), a utilização de maltodextrina em está generalizado na secagem de frutas para obtenção de pós, pois esse aditivo ajuda na prevenção do fenômeno da pegajosidade das partículas nas paredes da câmara do secador durante a desidratação de concentrados de frutas ou compostos com grandes quantidades de açúcares. 
Considerando a necessidade de estudos para preservação e agregação de valor à frutas, objetivou-se secar polpa de caju em secador de leito de jorro em diferentes temperaturas utilizandose maltodextrina como agente carreador, caracterizar físico-quimicamente os pós obtidos e avaliar o processo de secagem no secador utilizado.

\section{Material e Métodos}

\section{Matéria-Prima}

A polpa de caju utilizada nas secagens foi obtida no mercado varejista da cidade de Campina Grande-PB. Antes da aquisição da mesma, foi observado o modo de armazenamento da polpa, o estado de embalagem e o prazo de validade. Como agente carreador foi adicionado à polpa de caju a maltodextrina DE 14. Para preparação da formulação, a polpa de caju foi inicialmente descongelada à temperatura de refrigeração em geladeira doméstica, em seguida pesou-se $500 \mathrm{~g}$ da polpa e adicionou-se $10 \%$ de maltodextina. Essa formulação foi desidratada em secador de leito de jorro nas temperaturas de 50,60 e $70{ }^{\circ} \mathrm{C}$.

\section{Material Inerte}

O leito de partículas inertes, utilizado como suporte para as secagens da mistura de polpa de caju e maltodextrina, foi constituído por $1 \mathrm{~kg}$ partículas de polietileno do tipo 849, produzido pela EDN, Camaçari-BA. Essas partículas apresentavam as seguintes características físicas: diâmetro de $0,326 \mathrm{~cm}$, densidade de $1,045 \mathrm{~g} \mathrm{~cm}^{-3}$, porosidade de $0,411 \%$ e esfericidade de $0,8673 \%$, considerando a partícula como um cilindro elíptico.

\section{Secagem em Leito de Jorro}

O secador utilizado apresenta leito constituído de uma base cônica de aço inoxidável, com o ângulo interno de $110^{\circ}$, acoplada a uma coluna cilíndrica de vidro transparente que possibilita a visualização dos fenômenos, com diâmetro interno da coluna de $19 \mathrm{~cm}$, altura da coluna de $40,5 \mathrm{~cm}$ e diâmetro do orifício de entrada do ar de $4,4 \mathrm{~cm}$. O bico atomizador é instalado na parte superior do leito. A alimentação do atomizador é feita por linha de ar comprimido e pelo bombeamento da amostra de polpa de caju e maotodextrina. A separação e o recolhimento do pó são promovidos por um ciclone. $\mathrm{O}$ ar de secagem é proveniente de um soprador e aquecido em um trocador de calor com resistências elétricas de $3500 \mathrm{~W}$ de potência. Um controlador digital permite controlar o aquecimento do ar de secagem, a pressão interna da câmara, a vazão de ar e a vazão de suspensão 
do bico atomizador.ara condução dos experimentos, as partículas inertes foram colocadas na célula de secagem, a qual constituía o leito. Em seguida a célula foi acoplada a linha de secagem e, depois de atingida a temperatura de trabalho $\left(50,60\right.$ ou $\left.70{ }^{\circ} \mathrm{C}\right)$ iniciou-se a alimentação da polpa de caju e maltodextrina para o interior da câmara. A secagem foi da polpa foi processada pelo contato fluidopartícula e também pelo atrito entre os inertes, provocados pela alta taxa de circulação das mesmas no interior do leito. As polpas em pó foram coletadas em um recipiente de vidro acoplado na saída do ciclone.

Para cada temperatura de secagem $\left(50,60\right.$ ou $\left.70{ }^{\circ} \mathrm{C}\right)$ permaneceram constates os valores de vazão de ar (Var): jorro mínimo $\left(1,77 \mathrm{~m}^{3} \min ^{-1}\right)+30 \%=2,53 \mathrm{~m}^{3} \min ^{-1}$; vazão de suspensão do bico atomizador $\left(\mathrm{W}_{\mathrm{s}}\right)$ : $5 \mathrm{~g} \mathrm{~min}^{-1}$ e pressão interna: 0,03 bar. A temperatura de saída do ar de secagem (Tsaída) foi monitorada para cada temperatura de desidratação.

\section{Avaliação do Processo de Secagem}

Para avaliar o processo de secagem das amostras de polpa de caju e maltodextrina em leito de jorro, foram analisadas a taxa de recuperação do produto, a taxa de acúmulo no secador e a taxa de evaporação do leito de jorro.

A Taxa de recuperação do produto (rendimento) foi efetuado pela relação percentual entre a massa de pó total coletada pelo ciclone e a massa de sólidos alimentada ao equipamento e calculada pela Equação 1, de acordo com Souza (2003):

$$
\begin{aligned}
& \mathrm{R}(\%)=\frac{\mathrm{Mc}(1-\mathrm{Xp})}{\mathrm{Ws} \mathrm{c}_{\mathrm{g}} \theta} 100 \\
& \text { em que: } \\
& \mathrm{Mc}_{\mathrm{c}} \text { - massa coletada (g); } \\
& \mathrm{X}_{\mathrm{p}} \text { - umidade do produto; } \\
& \mathrm{W}_{\mathrm{s}} \text { - vazão de suspensão alimentada (g); } \\
& \mathrm{cs}_{\mathrm{s}} \text { - concentração de sólidos totais }(\mathrm{g}) ; \\
& \Theta \text { - tempo de processo (min). }
\end{aligned}
$$

A Taxa de acúmulo no secador de leito de jorro foi calculada pela relação entre a massa de material inerte antes e depois da secagem e o acumulo de material no secador de leito de jorro após o processo (SOUSA, 2003), de acordo com a Equação 2: 


$$
\begin{aligned}
& \text { Ac }(\%)=\frac{(M p f-M p i)(1-X p)}{W s c_{s} \theta} 100 \\
& \text { em que: } \\
& \text { Mpi - massa de partículas inertes inicial } \\
& (\mathrm{g}) ; \mathrm{Mpf} \text { - massa de partículas inertes final } \\
& (\mathrm{g}) ; \mathrm{X} \text { - umidade do produto; } \\
& \mathrm{W}_{\mathrm{s}} \text { - vazão de suspensão alimentada (g); } \\
& \mathrm{cs} \text { - concentração de sólidos totais (g); } \\
& \Theta \text { - tempo de processo (min). }
\end{aligned}
$$

A taxa de evaporação do leito de jorro durante os ensaios de secagem foi calculada a partir do seguinte balanço de massa (SOUZA, 2003):

$$
\begin{aligned}
& \mathrm{TE}=\frac{\mathrm{M}_{\mathrm{i}}-\mathrm{c}_{\mathrm{S}}}{\theta} \\
& \text { em que: } \\
& \mathrm{TE}=\text { Taxa de evaporação, } \mathrm{g} \mathrm{min}^{-1} ; \\
& \mathrm{M}_{\mathrm{i}}=\text { Massa inicial alimentada (g); } \\
& \mathrm{k}_{\mathrm{s}}=\text { Quantidade de sólidos da suspensão }(\mathrm{g}) ; \\
& \Theta=\text { tempo da operação de secagem (min). }
\end{aligned}
$$

\section{Caracterização Físico-Química}

A polpa de caju, a formulação de caju e maltodextrina e os pós produzidos nas secagens foram analisados quanto a umidade, sólidos totais, açúcares totais, acidez total titulável em ácido cítrico, pH e cinzas segundo o Instituto Adolfo Lutz (2008), ácido ascórbico pelo método de Tillmans (AOAC, 1997) modificado por Benassi \& Antunes (1998), atividade de água utilizando higrômetro AQUA-LAB, modelo CX-2, fabricado pela Decagon Devices e cor utilizando espectrofotômetro portátil MiniScan HunterLab XE Plus, modelo 4500 L, obtendo-se os seguintes parâmetros $L^{*}, a^{*}$ e $b^{*}$, em que $L^{*}$ define a luminosidade $\left(L^{*}=0\right.$ - preto e $L^{*}=100$ - branco) e $a^{*}$ e $b^{*}$ são responsáveis pela cromaticidade $\left(+a^{*}\right.$ vermelho e $-a^{*}$ verde; $+b^{*}$ amarelo e $-b^{*}$ azul).

\section{Análise Estatística}

Para a caracterização físico-química e a avaliação do processo de secagem, o delineamente experimental foi o de blocos inteiramente casualizados com três tipos de pós (secagem a 50, 60 e 70 
${ }^{\circ} \mathrm{C}$ ) e três repetições, utilizando-se o software Assistat. Os dados foram submetidos à análise de variância e a comparação de médias feita pelo teste de Tukey $(\mathrm{p} \leq 0,05)$.

\section{Resultados e Discussão}

\section{Características Físico-Químicas da Matéria-Prima}

Têm-se na Tabela 1 as análises físico-químicas realizadas na polpa integral e na polpa contendo $10 \%$ de maltodextrina. Observa-se que a adição desse carreador acarretou aumento significativo $(\mathrm{p}<0,05)$ nos sólidos totais, $\mathrm{pH}$ e açúcares totais, entretanto, constatou-se também redução $(\mathrm{p}<0,05)$ nos conteúdos de cinzas e na acidez total.

Tabela 1 - Análises físico-químicas das polpas de caju integral e com 10\% maltodextrina utilizadas nas secagens em leito de jorro.

\begin{tabular}{cccccc}
\hline Amostra & $\begin{array}{c}\text { Sólidos totais } \\
(\boldsymbol{\%})\end{array}$ & $\begin{array}{c}\text { Cinzas } \\
(\boldsymbol{\%})\end{array}$ & $\mathbf{p H}$ & $\begin{array}{c}\text { Acidez total } \\
(\boldsymbol{\%})\end{array}$ & $\begin{array}{c}\text { Açúcares totais } \\
(\boldsymbol{\%})\end{array}$ \\
\hline PI & $8,85 \pm 0,15^{\mathrm{b}}$ & $0,28 \pm 0,01^{\mathrm{a}}$ & $3,62 \pm 0,02^{\mathrm{a}}$ & $0,60 \pm 0,01^{\mathrm{a}}$ & $4,04 \pm 0,04^{\mathrm{b}}$ \\
PM & $17,23 \pm 0,22^{\mathrm{a}}$ & $0,23 \pm 0,02^{\mathrm{b}}$ & $3,73 \pm 0,02^{\mathrm{b}}$ & $0,52 \pm 0,01^{\mathrm{b}}$ & $4,44 \pm 0,04^{\mathrm{a}}$ \\
\hline
\end{tabular}

PI - polpa integral; PM - polpa com $10 \%$ de maltodextrina. Médias seguidas da mesma letra, na coluna, não diferem estaticamente a $5 \%$ de probabilidade pelo teste de Tukey.

Na Tabela 2 estão apresentadas as análises de atividade de água e de cor realizadas na polpa integral e na polpa contendo $10 \%$ de maltodextrina. Nota-se que todos os parâmetros analisados diferiram estatisticamente $(\mathrm{p}<0,05)$ ressaltando que a adição da maltodextrina alterou as características da amostra. A incorporação do carreador proporcionou obtenção de amostra mais clara $\left(\mathrm{L}^{*}\right)$, com redução das tonalidades verde $\left(-\mathrm{a}^{*}\right)$ e amarela $\left(+\mathrm{b}^{*}\right)$.

Tabela 2 - Análises de atividade de água e de cor das polpas de caju integral e com 10\% maltodextrina utilizadas nas secagens em leito de jorro.

\begin{tabular}{cccc}
\hline Amostra & Atividade de água (aw) & Luminosidade $\left(\mathbf{L}^{*}\right)$ & Cromaticidade $\mathbf{b}^{*}$ \\
\hline PI & $0,995 \pm 0,001^{\mathrm{a}}$ & $65,15 \pm 0,03^{\mathrm{b}}$ & $33,58 \pm 0,52^{\mathrm{a}}$ \\
PM & $0,993 \pm 0,001^{\mathrm{b}}$ & $71,79 \pm 0,29^{\mathrm{a}}$ & $29,21 \pm 0,43^{\mathrm{b}}$ \\
\hline
\end{tabular}

PI - polpa integral; PM - polpa com $10 \%$ de maltodextrina. Médias seguidas da mesma letra, na coluna, não diferem estaticamente a 5\% de probabilidade pelo teste de Tukey.

\section{Características Físico-Químicas dos Pós de Caju Produzidos}

A Tabela 3 apresenta os resultados das análises físico-químicas das polpas de caju em pó obtidas na secagem em leito de jorro nas temperaturas de 50, 60 e $70{ }^{\circ} \mathrm{C}$. O teor de umidade reduziu 
significativamente $(\mathrm{p}<0,05)$ com o aumento da temperatura de secagem, não sendo verificada diferença estatística entre os pós produzidos nas temperaturas de 60 e $70{ }^{\circ} \mathrm{C}$. Esse teor variou de $16,55 \pm 0,32 \%\left(50{ }^{\circ} \mathrm{C}\right)$ a $12,37 \pm 0,66 \%\left(70^{\circ} \mathrm{C}\right)$, estando semelhante à umidade encontrada por Lima et al. (1995) na polpa de acerola em pó obtida em secagem em leito de jorro (15,79\%). De acordo com Ferrari et al. (2012), o uso de temperaturas mais altas implica em uma maior taxa de transferência de calor para as partículas, o que leva a uma maior evaporação de água do produto, resultando em pós com umidade mais baixa, fenômeno este constatado nós pós da polpa de caju.

Tabela 3 - Análises físico-químicas das polpas de caju em pó obtidas na secagem em leito de jorro em diferentes temperaturas.

\begin{tabular}{|c|c|c|c|c|c|c|}
\hline C) & $\begin{array}{r}\text { Umidade } \\
(\%) \\
\end{array}$ & $\begin{array}{c}\text { Cinzas } \\
(\%)\end{array}$ & pH & $\begin{array}{c}\text { Acidez total } \\
(\%)\end{array}$ & $\begin{array}{c}\text { Açúcares totais } \\
(\%)\end{array}$ & saída $\left({ }^{\circ} \mathbf{C}\right)^{1}$ \\
\hline 50 & $16,55 \pm 0,32^{\mathrm{a}}$ & $1,44 \pm 0,07^{\mathrm{a}}$ & $3,99 \pm 0,01^{\mathrm{a}}$ & $1,82 \pm 0,04^{\mathrm{b}}$ & $24,34 \pm 0,42^{\mathrm{c}}$ & $45,78^{3}$ \\
\hline 60 & $14,09 \pm 0,71^{b}$ & $1,45 \pm 0,02^{\mathrm{a}}$ & $4,00 \pm 0,02^{\mathrm{a}}$ & $1,81 \pm 0,01^{\mathrm{b}}$ & $26,11 \pm 0,12^{b}$ & 40,09 \\
\hline 70 & $12,37 \pm 0,66^{b}$ & $1,57 \pm 0,05^{\mathrm{a}}$ & $3,93 \pm 0,01^{\mathrm{b}}$ & $2,32 \pm 0,05^{\mathrm{a}}$ & $28,56 \pm 0,15^{\mathrm{a}}$ & 44,07 \\
\hline
\end{tabular}

Houve concentração no conteúdo de cinzas dos pós de caju (Tabela 3) com o aumento da temperatura de secagem, no entanto não foi verificada diferença significativa pelo teste de Tukey. Essa concentração já era esperada, uma vez que a remoção da água acarreta acúmulo dos demais constituintes, como os minerais. Resultado semelhante foi reportado por Larrosa et al. (2011) em secagem de pasta de vegetais em secador de leito de jorro. Após secagem, os autores observaram considerável concentração dos minerais nos produtos desidratados.

Observou-se tendência significativa $(\mathrm{p}<0,05)$ de redução dos valores de $\mathrm{pH}$ (Tabela 3) do caju em pó com o aumento da temperatura de secagem à valor mais próximo ao $\mathrm{pH}$ da polpa com maltodextrina antes da desidratação. Comportamento oposto foi observado para a acidez total dos pós de caju, em que o aumento da temperatura favoreceu um aumento significativo $(\mathrm{p}<0,05)$ desse parâmetro. Diferentemente ao observado para o caju em pó, no estudo de Kha et al. (2010) foi reportado que a temperatura de secagem não influenciou estatisticamente o $\mathrm{pH}$ dos pós de frutos de Momordica cochinchinensis produzidos.

Os açúcares totais aumentaram significativamente $(\mathrm{p}<0,05)$ com a elevação da temperatura de secagem (Tabela 3), devido ao menor teor de umidade das amostras em pó ao final das desidratações, o que foi ocasionado por incremento na temperatura de desidratação. Os teores de açúcares variaram e $24,34 \pm 0,42 \%\left(50{ }^{\circ} \mathrm{C}\right)$ a $28,56 \pm 0,15 \%\left(70{ }^{\circ} \mathrm{C}\right)$, com um incremento de quase $15 \%$ de açúcares na amostra seca a $70{ }^{\circ} \mathrm{C}$. Esses resultados estão inferiores ao conteúdo de açúcares (36,55\%) reportado por Uchoa et al. (2008) para o caju em pó obtido através de secagem em estufa 
a vácuo. Contudo deve-se salientar que a umidade encontrada pelos autores foi de quase $7 \%$, sendo bastante inferior ao relatado neste estudo.

Os valores de atividade de água (aw) dos pós de caju (Tabela 4) reduziram significativamente $(\mathrm{p}<0,05)$ com o aumento da temperatura de secagem, sendo verificados, em todas as amostras, valores de aw inferiores a 0,6 , o que garante estabilidade dos pós durante a estocagem, conferindo-lhes, geralmente, vida de prateleira extensa. Tang \& Yang (2004) afirmam que aw inferior a 0,6 evita a deterioração de produtos em pó causada por micro-organismos e reações bioqímicas. Kha et al. (2010) e Ferrari et al. (2012), estudando a secagem de polpa de amora-preta e de Momordica cochinchinensis, respectivamente, também reportaram redução nos valores de aw com a elevação da temperatura de secagem, o que corrobora com os resultados desta pesquisa.

Nota-se que a temperatura de saída (Tabela 3) aumentou gradativamente com a elevação da temperatura de secagem (temperatura de entrada). Esta medição é um importante parâmetro da secagem, pois pode afetar a eficiência energética do secador e o conteúdo de umidade dos pós de caju produzidos (SILVA, 2002).

Tabela 4 - Análises de atividade de água e de cor das polpas de caju em pó obtidas na secagem em leito de jorro em diferentes temperaturas.

\begin{tabular}{lrrrr}
\hline$\left({ }^{\circ} \mathbf{C}\right)$ & Atividade de água $\left(\mathbf{a}_{w}\right)$ & Luminosidade $\left(\mathbf{L}^{*}\right)$ & Cromaticidade $^{*}$ & ${\text { Cromaticidade } \mathbf{b}^{*}}^{7}$ \\
\hline 50 & $0,318 \pm 0,001^{\mathrm{a}}$ & $68,13 \pm 0,09^{\mathrm{c}}$ & $2,57 \pm 0,04^{\mathrm{a}}$ & $29,79 \pm 0,09^{\mathrm{a}}$ \\
60 & $0,310 \pm 0,000^{\mathrm{b}}$ & $75,71 \pm 0,12^{\mathrm{b}}$ & $1,51 \pm 0,09^{\mathrm{b}}$ & $29,27 \pm 0,14^{\mathrm{b}}$ \\
70 & $0,308 \pm 0,000^{\mathrm{c}}$ & $82,38 \pm 0,06^{\mathrm{a}}$ & $-0,55 \pm 0,04^{\mathrm{c}}$ & $20,22 \pm 0,04^{\mathrm{c}}$ \\
\hline
\end{tabular}

Médias seguidas da mesma letra, na coluna, não diferem estaticamente a $5 \%$ de probabilidade pelo teste de Tukey.

Apesar de alguns autores (BADRIE; MELLOWES, 1991) afirmarem que a elevação da temperatura de secagem aumenta a intensidade da cor e os altos níveis de umidade resultam em produtos mais claros, proporcionando menor ocorrência de caramelização e reação de Maillard, foi verificado nas polpas de caju em pó que os produtos obtidos nas maiores temperaturas tiveram menor intensidade de cor e, apesar de terem apresentado menor umidade, não se apresentaram mais escuras (Tabela 4), em comparação ao pó produzido na temperatura mais baixa, o que contraria essa afirmação.

A luminosidade $\left(\mathrm{L}^{*}\right)$ do caju em pó variou de $68,13 \pm 0,09\left(50{ }^{\circ} \mathrm{C}\right)$ a $82,38 \pm 0,06\left(70{ }^{\circ} \mathrm{C}\right)$, com clareamento significativo $(\mathrm{p}<0,05)$ dos pós com o aumento da temperatura de secagem (Tabela 4). Resultado semelhante foi verificado por Larrosa et al. (2011) ao secarem pasta de vegetais em secador de leito de jorro. Esse fato pode estar relacionado à maior degradação de pigmentos 
ocasionada pela temperatura de secagem mais elevada. A cromaticidade $a^{*}$ variou significativamente $(\mathrm{p}<0,05)$ da tonalidade levemente avermelhada $\left(+\mathrm{a}^{*}\right)$, para os pós de caju produzidos nas temperaturas de 50 e $60{ }^{\circ} \mathrm{C}$, à tonalidade levemente esverdeada $\left(-\mathrm{a}^{*}\right)$, para o pó obtido à $70{ }^{\circ} \mathrm{C}$, com redução desses valores com o aumento da temperatura utilizada no leito de jorro. Quanto à cromaticidade b* (intensidade de amarelo) foi observado diminuição desses valores $(\mathrm{p}<0,05)$ com o aumento da temperatura de secagem, também relacionada à diluição da cor, concordando com Tonon et al. (2009) e Ferrari et al. (2012) que reportaram redução significativa da intensidade de amarelo em pós produzidos com amora-preta e açaí, respectivamente, ambas contendo maltodextrina em sua composição.

Apesar da utilização de maltodextrina como agente carreador, observou-se que os pós de caju produzidos a temperaturas mais baixas apresentam uma tendência de aglomeração, devido provavelmente às umidades mais elevadas (QUEK; CHOK; SWEDLUND, 2007). Isso está relacionado ao considerável teor de açúcares da amostra de polpa de caju e maltodextrina utilizada nas secagens (Tabela 1), uma vez que Ferrari et al. (2012) relatam que o os açúcares presentes nas frutas podem acarretar a obtenção de produtos com alta pegajosidade e higroscopicidade, diminuindo o rendimento do processo. Foi observado que o aumento da temperatura de secagem para $70{ }^{\circ} \mathrm{C}$ reduziu a formação de aglomerações no leito, diminuindo a retenção de sólidos. Apesar da aglomeração verificada nas secagens, não houve interrupção do jorro durante o processo. Resultados similares foram relatados por Larrosa et al. (2011) em estudo da secagem de pasta de vegetais em leito de jorro.

\section{Avaliação do Processo de Secagem}

Na Tabela 5 têm-se os valores médios dos parâmetros utilizados para avaliar o processo de secagem da suspensão de polpa de caju e maltodextrina em secador de leito de jorro.

Tabela 5 - Resultados referentes à avaliação do processo de secagem da suspensão de polpa de caju e maltodextrina em leito de jorro em diferentes temperaturas.

\begin{tabular}{rccccc}
\hline $\begin{array}{r}\text { Temp. } \\
\left({ }^{\circ} \mathbf{C}\right)\end{array}$ & $\begin{array}{c}\mathbf{W s} \\
\left(\mathbf{m L ~} \mathbf{~ m i n}^{\mathbf{- 1}}\right)\end{array}$ & $\begin{array}{c}\mathbf{V a r} \\
\left(\mathbf{m ~ s}^{-\mathbf{1}}\right)\end{array}$ & $\begin{array}{c}\mathbf{R} \\
(\boldsymbol{\%})\end{array}$ & $\begin{array}{c}\mathbf{A} \mathbf{c} \\
(\boldsymbol{\%})\end{array}$ & $\mathbf{E}$ \\
\hline 50 & 5,0 & 33,57 & $17,67^{\mathrm{c}}$ & $32,00^{\mathrm{a}}$ & $3,60^{\mathrm{a}}$ \\
\hline 60 & 5,0 & 33,57 & $18,75^{\mathrm{b}}$ & $27,92^{\mathrm{b}}$ & $3,60^{\mathrm{a}}$ \\
70 & 5,0 & 33,57 & $27,26^{\mathrm{a}}$ & $26,12^{\mathrm{c}}$ & $3,60^{\mathrm{a}}$ \\
\hline
\end{tabular}

Ws - Vazão de suspensão do bico atomizador; $\mathrm{V}_{\mathrm{ar}}$ - Velocidade do ar; $\mathrm{R}$ - taxa de recuperação do produto; Ac - taxa de acúmulo nas partículas; TE - taxa de evaporação. Médias seguidas da mesma letra, na coluna, não diferem estaticamente a $5 \%$ de probabilidade pelo teste de Tukey. 
Observa-se que a taxa de recuperação do produto (rendimento) aumentou significativamente $(\mathrm{p}<0,05)$ com o aumento da temperatura de secagem, atingindo valor superior a $27 \%$ no processo a $70{ }^{\circ} \mathrm{C}$

As menores taxas de recuperação nas temperaturas de secagem mais baixas devem-se a aglomeração dos pós produzidos nas partículas inertes e na parede da câmara devido a presença de açúcares, o que corrobora com os resultados de Medeiros et al. (2001), que afirmam que os açúcares interferem na eficiência de produção de pó no processo de secagem de polpa de frutas em leito de jorro com partículas inertes. Souza (2003) relata que a secagem em temperaturas mais elevadas promove produção de pó com menor teor de umidade, além de promover redução na umidade relativa do ar. Estes dois fatores levam a uma redução da aglomeração do produto com as partículas inertes e a câmera, sendo provavelmente a causa da tendência de aumento do rendimento com a elevação da temperatura de secagem das suspensões de caju e maltodextrina, uma vez que a vazão de suspensão do bico atomizador (Ws) e a velocidade do ar de secagem ( $\mathrm{V}_{\text {ar}}$ ) permaneceram constates (Tabela 5). Comportamento semelhante foi relatado por Larrosa et al. (2011) ao estudarem a secagem de pastas vegetais em secador de leito de jorro. Os autores reportaram que o aumento da temperatura do ar de secagem proporcionou um aumento gradual na eficiência de recuperação do pó.

A taxa de acúmulo do material no secador de leito de jorro (Tabela 5) diminuiu significativamente $(\mathrm{p}<0,05)$ com $\mathrm{o}$ aumento da temperatura de secagem, devido à menor aglomeração de pó formada no secador. Esses resultados ainda podem estar relacionados ao fato do material mais seco se desprender com maior facilidade das partículas inertes que o mais úmido (LARROSA; MUSZINSKI; PINTO, 2011). Apesar de tendência de redução de acumulo com o aumento da temperatura de secagem, nota-se que esta foi superior a $26 \%$ em todos os experimentos. Segundo Medeiros et al. (2001), o acumulo de material se constitui um dos graves problemas deste secador, chegando até mesmo a inviabilizar sua utilização na secagem de diversos materiais.

Quanto a taxa de evaporação (Tabela 5), nota-se que esta se manteve estável em todos os experimentos, uma vez que não houve alteração na vazão de suspensão do bico atomizador, o que levou a um igual consumo de ar por massa de água evaporada.

\section{Conclusão}

O aumento da concentração de maltodextrina resultou em pós com menores teores de água, atividade de água, cinzas, acidez titulável, ácido ascórbico, açúcares totais, açúcares redutores eintensidades de vermelho e de amarelo. Apesar de serem detectadas reduções também em termos nutricionais, os cajus em pó obtidos com maior conteúdo de agente carreador apresentaram melhor 
qualidade em relação à facilidade de manipulação e escoabilidade, além do potencial em reduzir gastos com transporte e estocagem, devido à redução de massa e de volume.

A obtenção da polpa de caju em pó constitui-se em mais uma opção de renda para a agricultura familiar, uma vez que agrega valor ao fruto, ao passo que disponibiliza a indústria de produtos agroindustriais mais uma matéria-prima que pode ser incorporada em novos produtos.

\begin{abstract}
The objective of cashew pulp drying in spouted bed dryer, characterize the physico-chemically produced powders and evaluate the drying process used in the dryer. The cashew pulp was added to $10 \%$ maltodextrin and subjected to drying at temperatures of 50, 60 and $70{ }^{\circ} \mathrm{C}$. The powders produced were analyzed for moisture content, total sugars, total acidity as citric acid, pH, ash content, water activity and color, to obtain the parameters of lightness $\left(L^{*}\right)$, and Chromaticities a* and $b^{*}$. As for the drying process were evaluated the rate of removal of product (yield), the accumulation rate in the drier and the rate of evaporation of the spouted bed. It was observed that the moisture content, water activity and $\mathrm{pH}$ significantly reduced with increasing drying temperature. There concentration of ash and significant increase in the amounts of sugars and acidity with increasing temperature. The temperature elevation drying promoted significant whitening in powders. The recovery rate of the product increased with increased drying temperature and accumulation rate decreased with temperature. The evaporation rate did not change. The spouted bed drying is a good choice for obtaining the cashew pulp powder, with best results the parameters analyzed for the powder produced at $70^{\circ} \mathrm{C}$.
\end{abstract}

Key-words: Anacardium occidentale L., dehydration, quality control, chemical analysis.

\title{
Referências
}

ALCÂNTARA, S. R. et al. Isotermas de adsorção do pedúnculo seco do caju. Revista Brasileira de Engenharia Agrícola e Ambiental, v. 13, n. 1, p. 81-87, 2009. http://dx.doi.org/10.1590/S1415-43662009000100012

ALMEIDA, C.; ROCHA, S. C. S. Fluidodinâmica de sementes de brócolos em leito fluidizado e leito de jorro. Scientia Agricola, v. 59, n. 4, p. 645-652, 2002. http://dx.doi.org/10.1590/S0103-90162002000400004

AOAC - Association of Official Analytical Chemists. Official Methods of Analysis. WILLIAMS, S. (Ed.) $14^{\mathrm{a}}$ ed, Arlington, USA: AOAC, 1997. 1041 p.

BENASSI, M. T.; ANTUNES, A. J. A. Comparison of meta-phosphoric and oxalic acids as extractant solutions for determination of vitamin $C$ in selected vegetables. Arquivos de Biologia e Tecnologia, v. 31, n. 4, p. 507-503, 1998.

BEZERRA, C. V. et al. Green banana (Musa cavendishii) flour obtained in spouted bed - Effect of drying on physicochemical, functional and morphological characteristics of the starch. Industrial Crops and Products, v. 41, n. 1, p. 241-249, 2013. http://dx.doi.org/10.1016/j.indcrop.2012.04.035BADRIE, N.; MELLOWES, W. A. Effect of extrusion variables on cassava extrudates. Journal of Food Science, v. 56, n. 5, p. 1334-1337, 1991. http://dx.doi.org/10.1111/j.1365-2621.1991.tb04766.x

CABRAL, R. A. F. et al. Effect of apparent viscosity on fluidized bed drying process parameters of guava pulp. Journal of Food Engineering, v. 80, n. 4, p. 1096-1106, 2007. http://dx.doi.org/10.1016/j.jfoodeng.2006.09.002

FERRARI, C. C.; RIBEIRO, C. P.; AGUIRRE, J. M. Secagem por atomização de polpa de amora-preta usando maltodextrina como agente carreador. Brazilian Journal of Food Technology, v.15, n.2, p.157-165, 2012. http://dx.doi.org/10.1590/S1981-67232012005000009

GOMES, P. M. A.; FIGUEIRÊDO, R. M. F.; QUEIROZ, A. J. M. Armazenamento da polpa de acerola em pó a temperatura ambiente. Ciência e Tecnologia de Alimentos, v. 24, n. 3, p. 384-389, 2004. http://dx.doi.org/10.1590/S0101-20612004000300014 
INSTITUTO ADOLFO LUTZ. Normas analíticas, métodos químicos e físicos para análises de alimentos. $4^{\mathrm{a}}$ ed. $1^{\mathrm{a}}$ ed. Digital, São Paulo: IAL, 2008. 1020 p.

KHA, T. C.; NGUYEN, M. H.; ROACH, P. D. Effects of spray drying conditions on the physicochemical and antioxidant properties of the Gac (Momordica cochinchinensis) fruit aril powder. Journal of Food Engineering, v. 98, n. 3, p. 385-392, 2010. http://dx.doi.org/10.1016/j.jfoodeng.2010.01.016

LARROSA, A. P. Q.; MUSZINSKI, P.; PINTO, L. A. A. Programação linear para formulação de pasta de vegetais e operação de secagem em leito de jorro. Ciência Rural, v. 41, n. 11, p. 2032-2038, 2011. http://dx.doi.org/10.1590/S0103-84782011001100030

LIMA, M. L. et al. Desidratação de polpas de frutas tropicais em leito de jorro. In: CONGRESSO BRASILEIRO DE ENGENHARIA QUÍMICA., 1. Anais... SBQ: São Carlos, 1995, p. 121-123.

MARTINS, P. C. Estudo da influência de uma fase lipídica na aglomeração de pós alimentícios. Campinas, 2006. 178p. Tese (Doutorado em Engenharia de Processos) - Universidade Estadual de Campinas.

MEDEIROS, M. F. D. et al. Escoabilidade de leitos de partículas inertes com polpa de frutas tropicais. Efeitos na secagem em leito de jorro. Revista Brasileira de Engenharia Agrícola e Ambiental, v. 5, n. 3, p. 475-480, 2001. http://dx.doi.org/10.1590/S1415-43662001000300018

MELO, K. S. et al. Fluidodinâmica de leito de jorro com leite de cabra e polpa de cajá. Revista Verde, v. 5, n. 4, p. 6167,2010

PALLAI, E.; SZENTMARJAY, T.; MUJUMDAR, A.S. Spouted bed drying. In: MUJUMDAR, A. (Ed). Handbook of industrial drying. Philadelphia: Taylor \& Francis Group, $2006 . \quad$ Cap.14, p.363-384. http://dx.doi.org/10.1201/9781420017618.ch14

PEREIRA, J. M. A. T. K. et al. Avaliação da qualidade físico-química, microbiológica e microscópica de polpas de frutas congeladas comercializadas na cidade de Viçosa-MG. Alimentos e Nutrição, v. 17, n. 4, p. 437-442, 2006.

PINHO, L. X. et al. Desidratação e aproveitamento de resíduo de pedúnculo de caju como adição de fibra na elaboração de hambúrguer. Alimentos e Nutrição, v. 22, n. 4, p. 571-576, 2011.

QUEK, S. Y.; CHOK, N. K.; SWEDLUND, P. The physicochemical properties of spray-dried watermelon powder. Chemical Engineering and Processing: Process Intensification, v. 46, n. 5, p. 386-392, 2007. http://dx.doi.org/10.1016/j.cep.2006.06.020

SANCHO, S. O. et al. Alterações químicas e físico-químicas no processamento de suco de caju (Anacardium occidentale L.). Ciência e Tecnologia de Alimentos, v. 27, n. 4, p. 878-882, 2007. http://dx.doi.org/10.1590/S010120612007000400031

SILVA, T.A.C. Caracterização bioquímica e secagem em "spray dryer" de lípases produzidas pelo fungo endofítico Cercospora kikuchii. Ribeirão Preto, 2010. 106f. Dissertação (Mestrado em Ciências Farmacêuticas) Universidade de São Paulo.

SOUZA, C. R. F. Estudo comparativo da produção de extrato seco de Bauhinia forficata Link pelos processos de spray-dryer e leito de jorro. Ribeirão Preto, 2003. 180f. Dissertação (Mestrado em Ciências Farmacêuticas) Universidade de São Paulo.

TANG, J.; YANG, T. Dehydrated vegetables: principles and systems. In: HUI, Y.H. et al. (Ed.). Handbook of vegetable preservation and processing. Marcel Dekker, New York, 2004.

TONON, R. V.; BRABET, C.; HUBINGER, M. D. Influência da temperatura do ar de secagem e da concentração de agente carreador sobre as propriedades físico-químicas do suco de açaí em pó. Ciência e Tecnologia de Alimentos, v. 29, n. 2, p. 444-450, 2009. http://dx.doi.org/10.1590/S0101-20612009000200034 
UCHOA, A. M. A. et al. Parâmetros físico-químicos, teor de fibra bruta e alimentar de pós alimentícios obtidos de resíduos de frutas tropicais. Segurança Alimentar e Nutricional, v. 15, n. 2, p. 58-65, 2008.

Submetido em 19 ago. 2014, Aceito para publicação em 11 jan. 2015, Publicado em 10 dez. 2015. 